Int. J. Med. Surg. Sci,

4(1):1115-1118, 2017.

\title{
Gigantic Reactive Lesion of Mandibular Gingival Tissue
}

\author{
Lesión Gigante Reactiva del Tejido Gengival Mandibular
}

M. K. Guptaㄹ; Ajit Joshi1; Monica Mahajan¹ \& Akshay Mishra

GUPTA, M. K.; JOSHI, A.; MAHAJAN, M. \& MISHRA, A. Gigantic reactive lesion of mandibular gingival tissue. Int. J. Med. Surg. Sci., 4(1):1115-1118, 2017.

SUMMARY: Irritation fibroma are the most common form of reactive lesions found within the oral cavity. These lesions normally attain a small size and show a slow growth rate. This paper reports a case of gigantic intraoral irritational fibroma with a history of rapid growth. Complete excision was performed and the specimen was sent for immunohistochemistry (IHC) staining. It was found positive for vimentin, hence reported as irritation fibroma.

KEY WORDS: Oral Irritation Fibroma; Immunohistochemistry; Vimentin.

\section{INTRODUCTION}

Fibroma is the most common benign soft tissue tumor of oral cavity. These are basically mesenchymal tumors consisting of fibrous connective tissue. There are two types of Fibroma- "Irritation Fibroma" (Peripheral fibroma/ Gingival fibroma/ Focal fibrous hyperplasia) and "True Fibroma". Irritation fibroma is the most common tumour of oral cavity, but it represents most likely as a reactive hyperplasia of fibrous connective tissue in response to local trauma (Kar et al., 2015; Kinoshita et al., 2016). Clinically it is difficult to distinguish between the reactive hyperplasia and true neoplasms of the oral cavity (Kinoshita et al.). True fibroma rarely occurs in oral and maxillofacial region (Kar et al.). A fibroma may occur at any oral site but is seen most often on the buccal mucosa along the plane of dental occlusion, labial mucosa and tongue (Biswas et al., 2015). It is commonly seen in females in their 3rd, 4th \& 5th decades of life (Redman et al., 2013). While it does not generally exceed the size of $1 \mathrm{~cm}$ (Bagde et al., 2013; Redman et al.; Biswas et al.) but there have been a few cases reported where such lesions have attained a huge size (Biswas et al.; Kar et al.; Kinoshita et $a /$.$) . Here this case report of a gigantic oral$ irritational fibroma of oral cavity with comparatively shorter history of growth period.

\section{Case History}

A 36 years old female reported to the Department of Oral \& Maxillofacial Surgery, with a chief complaint of a large, painless intraoral growth in the lower left side of jaw since 6 to 8 months. She had habit of toothpick application and usage of an abrasive dentifrice. The growth was initially peanut size and progressively increased to attain a present size $\left(6 \times 5 \times 3 \mathrm{~cm}^{2}\right.$ approximately) (Fig. 1). Eventually, she stopped the use of dentifrice and claimed that the growth neither increased nor decreased since 1 month. There is a history of exfoliation of a tooth from the same region about 10 days back. She had habit of betel nut consumption everyday for last 8-10 years but recently stopped it since 5-6 months. Extraoral examination showed no gross

${ }^{1}$ Oral \& Maxillofacial SurgerySwargiya Dadasaheb Kalmegh Smruti Dental College \& Hospital, Nagpur, India. 
facial asymmetry. Intraoral examination revealed a huge pedunculated, multilobulated gingival growth of size approximately $6 \times 5 \times 3$ $\mathrm{cm}^{2}$ extending from distal to 33 till the mesial to 38 . The growth was pink in color with smooth surface and 3 lobes. Its pedicle was attached to the mesial interdental papilla adjacent to the exfoliated left mandibular first molar. The lesion was movable in all directions and its pedicle could be very well appreciated. Adjacent to the growth, both the premolars were grade III mobile and lingually displaced. The lesion was non-tender and had variable consistency over its different regions. The oral hygiene was not appreciable and halitosis was present.

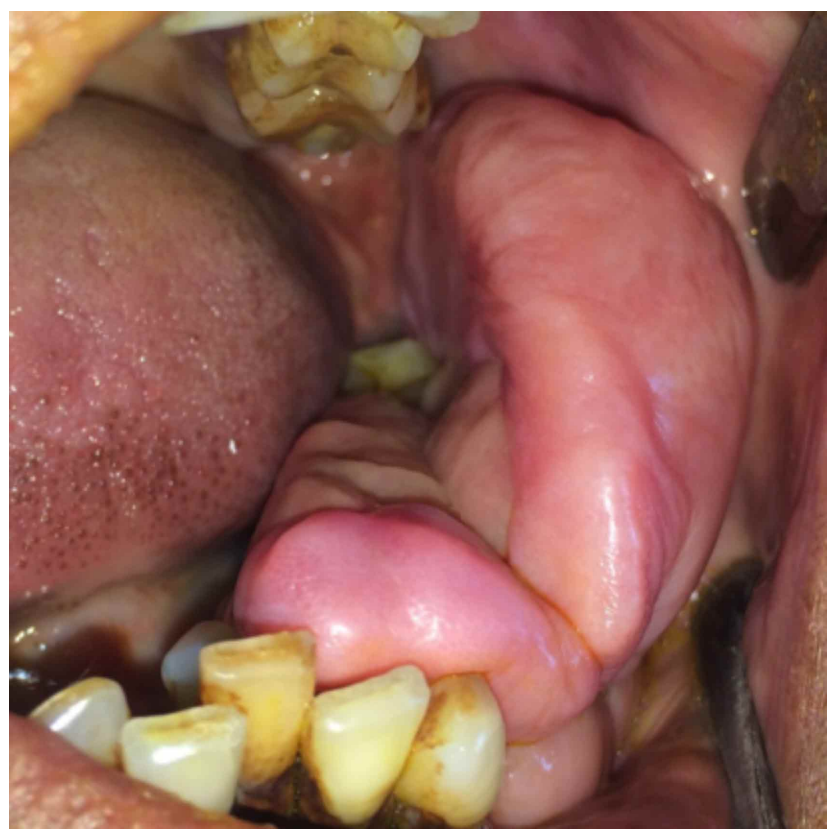

Fig. 1 Intraoral pedunculated lesion.

Routine complete blood count was performed and informed written consent was obtained. Radiological examination (Orthopantomograph) revealed generalized bone loss. Incisional biopsy was carried out and histopathological examination revealed as a fibroma. Surgical removal of the lesion was planned. Ligation of pedicle was followed by wide local surgical excision of the lesion under local anesthesia. The first and second premolars were extracted and peripheral ostectomy was accomplished. Margins of the mucosa were undermined and complete hemostasis was achieved. Closure was performed with 3-0 mersilk. The excised specimen was sent for histopathological examination (Fig. 2). Hematoxyline and Eosine staining reported presence of abundant delicate collagen fibers arranged irregularly throughout the connective tissue with many stellate spindle shaped fibroblasts and blood capillaries of variable sizes (Fig. 3). A few areas of the specimen show presence of myxoid tissue with delicate fibers \& stellate shaped cells with very few

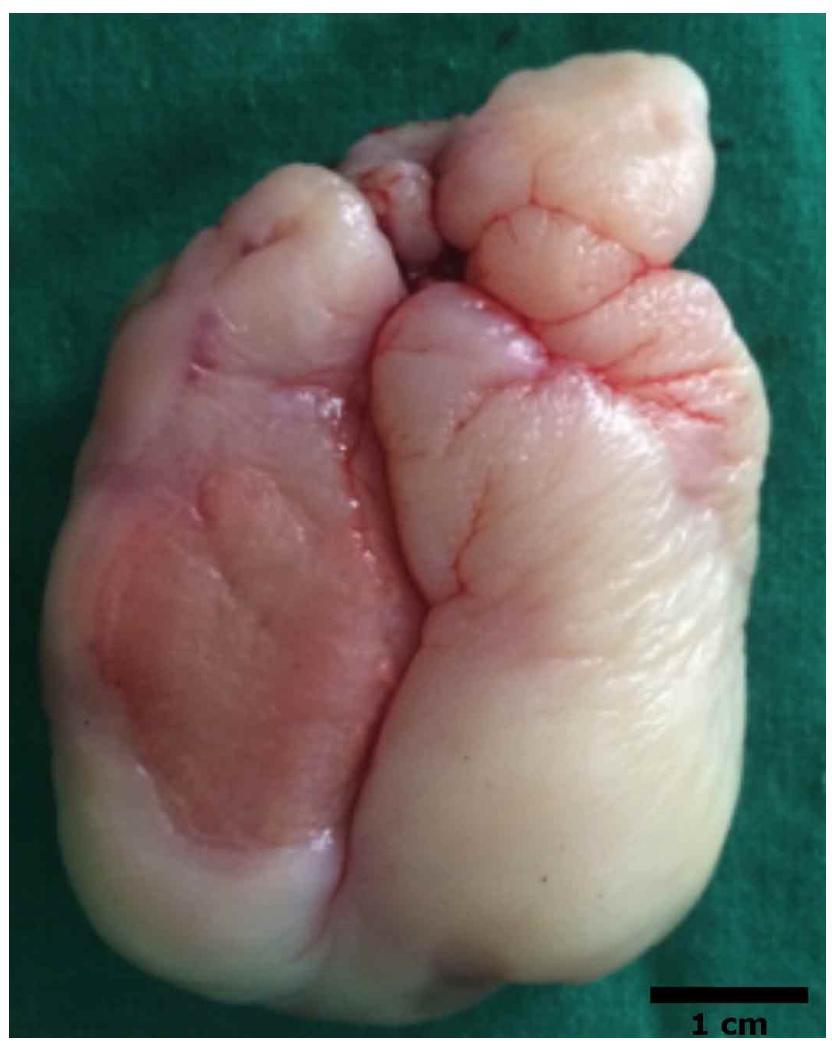

Fig. 2 Excised specimen.

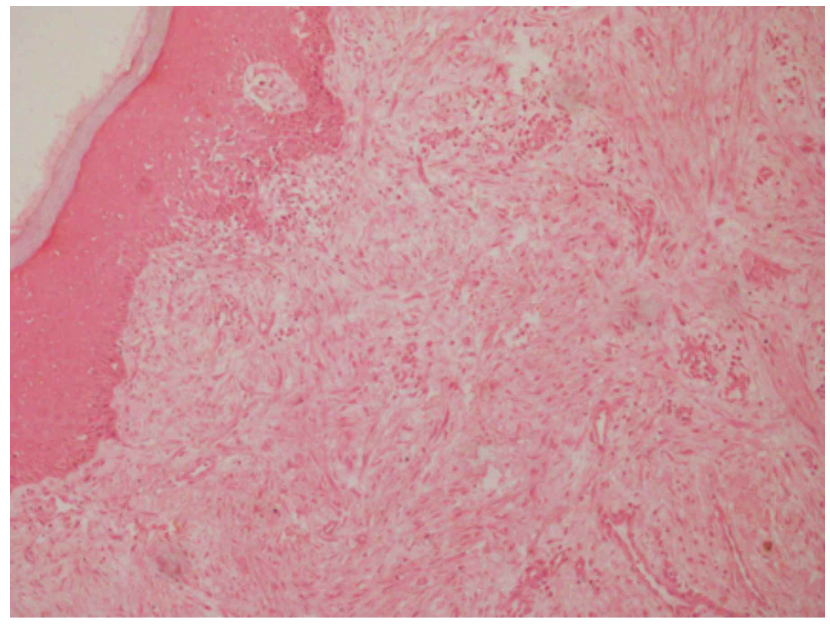

Fig. 3. Biosy of the excised specimen. H\&E 10x. 
multinucleated giant cells. Some areas revealed presence of neural tissue which raised the suspicion of the lesion to be having some neural component such as that of neurofibroma. But immunohistochemistry staining revealed the lesion to be positive for Vimentin (marker for fibroma) (Kinoshita et al.) and negative for S100 (marker for neurofibroma) (Fig. 4). Thus a definitive diagnosis of Irritation Fibroma was justified. Follow-up of 14 months showed no signs of recurrence.

\section{DISCUSSION}

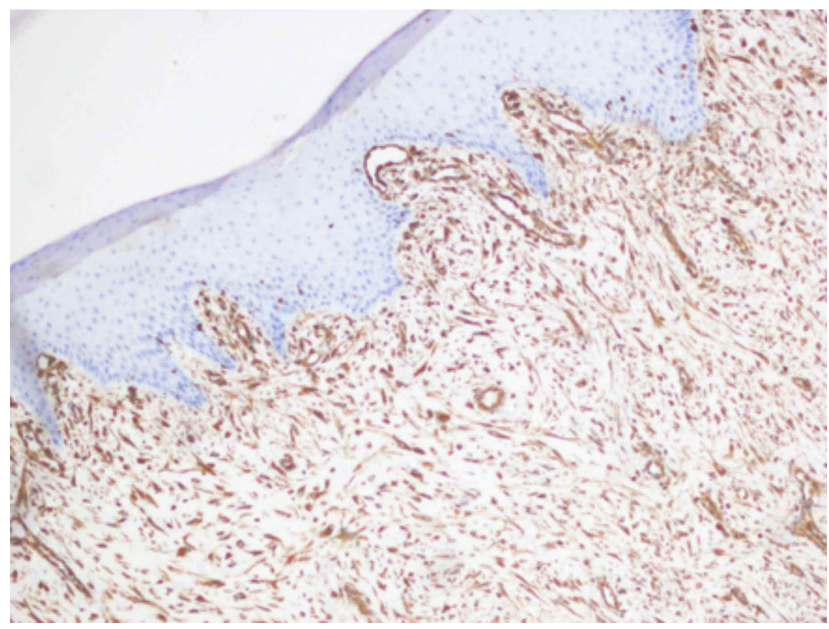

Fig. 4. IHC staining of the excised specimen positive for Vimentin (10x)

Fibroma is the most common benign soft tissue tumor of oral cavity. Generally, fibromas represent slow growing reactive focal fibrous hyperplasia due to trauma or local irritation (Nakamura et al., 2005). Biswas et al. stated that hyperplasia unlike neoplasia is a self-limiting process and hyperplastic cells sometimes show regression after removal of the stimulus. Fibroma generally presents as a painless, sessile, round or ovoid, broad based growth. Its color is same or lighter than surrounding tissue due to a reduced vascularity (Esmeili et al., 2005). It has a pedunculated or a sessile base and is non tender unless ulcerated or secondarily infected. Redman et al. stated that fibroma is formed as a result of a chronic repair process that includes granulation tissue and scar formation resulting in a submucosal fibrous mass. Recurrences are generally rare and may be caused by repetitive trauma at the same site. Regezzi et al. (2008) stated that foci of chronic inflammation and granulation tissue, especially near the base where calculus and other irritants may have lodged, seem to be the source of growth. Occasionally, granulation tissue is concentrated on or near the surface, and the resulting red color makes the lesion resemble a Pyogenic Granuloma. These lesions usually don't transform into malignancy. The most common sites of traumatic fibroma are the tongue, buccal mucosa, and lower labial mucosa. Kinoshita et al. stated that the size of fibromas usually remains small, and cases that are $>1.0 \mathrm{~cm}$ in diameter are rare. Literature reported very few cases of large irritation fibroma of $>4.0 \mathrm{~cm}^{2}$ such as those by Fonseca et al. (2014) and Kinoshita et al. Most of these occurred on palate and buccal mucosa and were slow growing lesions (Fonseca et al.; Kar et al.; Kinoshita et al.).

This reported case is of a gigantic intraoral fibroma occurring on mandibular gingival with a short history of onset. In this case the potential irritants were found to be use oftoothpicks, abrasive dentifrice and chronic irritation by plaque and calculus which could have been the source for the development of this lesion in such a short period of 6 months. Habit of consuming betel nut may also attribute to the irritation of gingival tissue in that region.

There are many treatment options for the management of oral irritation fibroma- surgical excision, cautery and laser surgery. Biswas et al. reported com-plications with conventional surgery such as intra and post-operative bleeding, difficulties in wound healing, swelling, scarring and postsurgical pain. But, in general, excision under Local anesthesia is found to be most cost effective treatment with excellent results.

\section{CONCLUSION}

Among the lesions affecting the oral cavity, reactive lesions constitute the most common type of these lesions. Oral fibroma corresponds to reactive focal fibrous hyperplasia which is always due to trauma or local irritation. This 
case shows an unusually large oral irritation fibroma of mandibular gingiva and it is unique in its way because of its huge size and history of growth relatively of shorter duration, which is generally not seen in case of fibroma. Investigation by immunohistochemistry confirmed the histopathological diagnosis, but it has definitely put forth a question regarding the underlying pathophysiology for the growth of such a gigantic lesion in a short period of time. Thus further study is required to assess the nature of such lesions.

\section{ACKNOWLEDGEMENT}

We acknowledge the Department of Oral Pathology and Microbiology of Swargiya Dadasaheb Kalmegh Smruti Dental College \& Hospital, Hingna, Nagpur, VSPM DCRC, Hingna, Nagpur and General Pathology Department, RST, Nagpur for their help and support for Histopathological and IHC reporting and photographs.

GUPTA, M. K .; JOSHI, A .; MAHAJAN, M. \& MISHRA, A. Lesión gigante reactiva del tejido gengival mandibular. Int. J. Med. Surg. Sci., 4(1):1115-1118, 2017.

RESUMEN: Los fibromas irritativos son las forma más común de lesiones reactivas encontradas en la cavidad oral. Estas lesiones normalmente son de pequeño tamaño y muestran una tasa de creciemiento lenta. Este artículo reporta el caso de un fibroma irritativo gigante intraoral con historia de crecimiento rápido. Se realizó la extirpación completa y fue enviado para análisis inmunohistoquímico. Arrojó positivo para Vimentina, por lo tanto, se reportó como fibroma irritativo.

PALABRAS CLAVE: Fibroma oral por irritación ; Inmunohistoquímica; Vimentina.

\section{REFERENCES}

Bagde, H.; Waghmare, A.; Savitha, B. \& Vhanmane, P. Irritation fibroma - A case report. Int. J. Dent. Clin., 5(1):39-40, 2013.

Biswas, S.; Anuroopa, P. \& Savita, S. A report of solitary large buccal fibroma treated using diode laser: 6 month follow up. J. Evol. Med. Dent. Sci., 4(7):1278-82, 2015.

Esmeili, T.; Lozada-Nur, F. \& Epstein, J. Common benign oral soft tissue masses. Dent. Clin. North Am., 49(1):223-40, 2005.

Fonseca, G. M.; Fonseca, R. M. \& Cantin, M. Massive fibrous epulis-a case report of a 10-year-old lesion. Int. J. Oral Sci., 6(3):182-4, 2014.

Kar, C.; Sarkar, P.; Das, S. \& Ghosh, A. Large irritation fibroma of palate - A rare presentation. J. Pak. Assoc. Dermatol., 25 (3):233-6, 2015.

Kinoshita, H.; Ogasawara, T.; Toya, T.; Makihara. R.; Hirai, R. \& Kawahara, E. Slow-growing large irritation fibroma of the anterior hard palate: A case report using immunohistochemical analysis. J. Maxillofac. Oral Surg., 15(Suppl. 2):253-7, 2016.

Nakamura, F.; Fifita, S. F. \& Kuyama, K. A study of oral irritation fibroma with special reference to clinicopathological and immunohistochemical features of stromal spindle cells. Int. J. Oral Med. Sci., 4(2):83-91, 2005.

Regezzi, J. A. ; Sciubba, J. J. \& Jordan, R. C. K. (Eds.). Oral Pathology. Clinical Pathologic Correlations. $5^{\text {th }}$ ed. St. Louis, W. B. Saunders, 2008.

Redman, R. S.; Chauhan, S. \& Paul, B. F. Slowly enlarging gingival mass in a 50-year-old man. Oral Surg. Oral Med. Oral Pathol. Oral Radiol., 116(2):135-41, 2013.

Corresponding author

Dr. Ajit Joshi

Oral \& Maxillofacial Surgery

Swargiya Dadasaheb Kalmegh Smruti Dental College \& Hospital

Oral \& Maxillofacial Surgery

Nagpur

INDIA

E-mail:dr.ajitjoshi@yahoo.in

Received: 20-01-2017

Accepted: 16-02-2017 